\title{
An aspirin a day may not be enough
}

\author{
Paul J. Chai, MD
}

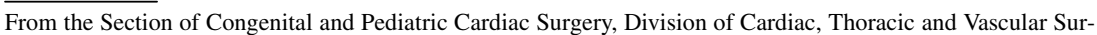
gery, New York-Presbyterian Morgan Stanley Children's Hospital, Columbia University Medical Center, New York, NY.

Disclosures: Author has nothing to disclose with regard to commercial support.

Received for publication July 27, 2017; accepted for publication July 31, 2017.

Address for reprints: Paul J. Chai, MD, Section of Congenital and Pediatric Cardiac Surgery, Division of Cardiac,

Thoracic and Vascular Surgery, New York-Presbyterian Morgan Stanley Children's Hospital, 3959 Broadway,

New York, NY 10032 (E-mail: pjc2164@ cumc.columbia.edu).

J Thorac Cardiovasc Surg 2017;154:1714

$0022-5223 / \$ 36.00$

Copyright (c) 2017 by The American Association for Thoracic Surgery

http://dx.doi.org/10.1016/j.jtcvs.2017.07.059

The article in this issue of the Journal by Emani and colleagues ${ }^{1}$ from Boston examines the utility of laboratory testing for aspirin efficacy in pediatric cardiac surgical patients. This is a retrospective study of 430 pediatric patients who received aspirin after cardiac surgery. Emani and colleagues $^{1}$ sought to determine the association between platelet testing and thrombosis rates in cardiac surgical patients at high risk for thrombosis after surgery. Aspirin unresponsiveness was detected in 64 patients $(15 \%)$, with thrombosis in 11 patients $(2.6 \%)$. In most cases, aspirin was started after 2 to 5 days of the administration of unfractionated heparin. Aspirin was given at a dose of 3- to 10-mg/ $\mathrm{kg} / \mathrm{d}$. Thrombosis events were recorded as symptomatic events (stroke, limb ischemia, shunt thrombosis) or asymptomatic evidence of thrombus (evidence on echocardiography or cardiac catheterization).

Emani and colleagues ${ }^{1}$ found an association between aspirin unresponsiveness on initial testing (threshold of 550 aspirin reaction units by VerifyNow Aspirin System [Accriva Diagnostics, San Diego, Calif] indicating subtherapeutic platelet inhibition ${ }^{2}$ ) and thrombotic events. They also found that $37 \%$ of patients who did not have dose adjustment after inadequate response to aspirin had thrombotic events, whereas those who did have dose increases on the basis of testing did not have subsequent thrombosis.

The study is an intriguing one, because the ability to assess aspirin responsiveness adequately would potentially provide value in various clinical scenarios. It is difficult to interpret the findings of the study, however, because the overall incidence of thrombosis was low (11 of 430 patients). The study is also limited by its retrospective nature, because the clinical management of all these patients was not consistent. For instance, not all patients who were found to have subtherapeutic responses were treated identically. In addition, the diagnosis of thrombosis seems inexact and widely variable (stroke, limb ischemia, shunt thrombosis, and so on). The study could have been strengthened if the

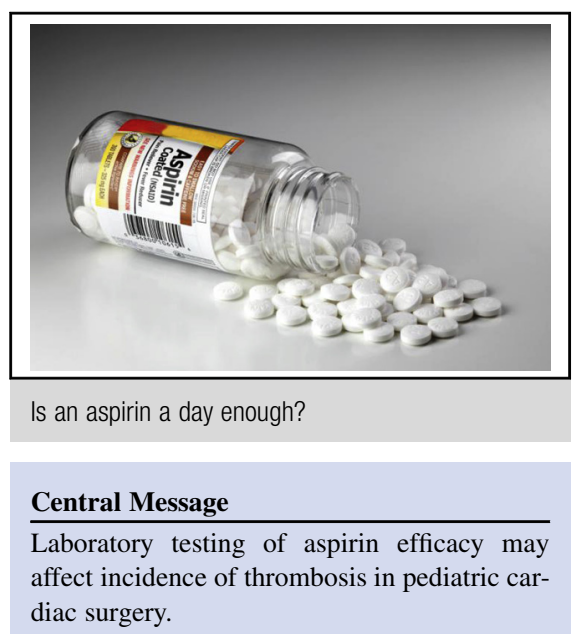

See Article page 1723 .

cohort of patients had been narrowed and more consistent (eg, just looking at patients with shunt thrombosis). Most of the end points of thrombosis could be the result of other factors, not related to aspirin. For instance, stroke could be caused by bleeding or embolus, and shunt thrombosis may be related to technical issues. In fact, most of the patients who had thrombosis were excluded because the events occurred before aspirin use but during administration of heparin, suggesting that many factors are involved (not just the degree of anticoagulation). As a result, it seems difficult to conclude that the end result of thrombosis was caused by poor aspirin efficacy when the nature of thrombotic events was so varied and could easily be accounted for by other factors.

The notion of testing for aspirin effectiveness in postoperative cardiac patients certainly makes sense, and Emani and colleagues ${ }^{1}$ are to be commended for examining this. The study's findings certainly make logical sense, but we need to be cautious in drawing any definitive conclusions from the study.

\section{References}

1. Emani S, Zurakowski D, Moline M, DiNardo JA, Treanor CC III, Emani SM. Platelet testing to guide aspirin dose adjustment in pediatric patients following cardiac surgery. J Thorac Cardiovasc Surg. 2017;154:1723-30.

2. Collet JP, Cuisset T, Rangé G, Cayla G, Elhadad S, Pouillot C, et al; ARCTIC Investigators. Bedside monitoring to adjust antiplatelet therapy for coronary stenting. N Engl J Med. 2012;367:2100-9. 